\title{
Formulasi Pembuatan Minuman Herbal dari Campuran Sari Jahe dan Temulawak
}

\section{Formulation for Making Herbal Drinks from a Mixture of Ginger and Temulawak}

\author{
Dewi Restuana Sihombing \\ Program Studi Teknologi Hasil Pertanian, Universitas Katolik Santo Thomas Medan \\ email : dewirestuanasihombing@gmail.com
}

\begin{abstract}
The aim of this research is to produce a herbal drink with a fortifying by concentrate of ginger and curcuma. Be side of that it also to useful as a reference to making a herbal drink from mixture by ginger and curcuma. This research was conducted at the laboratory of Agricultural Products Processing Faculty of Agriculture. The experiment was performed with using completely randomized design (CRD) factorial, that consist of two treatment factors. The first factors by concentrate of ginger and curcuma with a encode J, consisting by 4 levels, that were: $J o=80: 20, J 1=70: 30, J 2=60: 40$, dan J3=50:50. The second factor is duration of storage with a encode $L$, consisting by 4 levels, that were: $L O=0$ weeks, $L 1=$ 1 weeks and $L 2=2$ weeks, and $L 3=3$ weeks. Ratio of treatment by concentrate of ginger and curcuma give a real effect to these fourth parameter that were total soluble solid (tss), $\mathrm{pH}$, total acid, and organoleptic value. The treatment of duration storage ( 0 weeks, 1 weeks, 2 weeks, and 3 weeks) have a real effect to these fourth parameter that were total soluble solid (tss), pH, total acid, and organoleptic value. And on the graph for total soluble solid (tss) and total acid have experience more increasing, but for $\mathrm{pH}$ and organoleptic value have experience is decreased with every weeks. And for combination by treatment of ratio the concentration of ginger and curcuma have a real effect on the organoleptic value, but not have a real effect on total soluble solid (tss), $\mathrm{pH}$ and total acid.
\end{abstract}

\section{Keywords: Herbal Drink, Ginger extract, Temulawak, Storage Time}

\section{ABSTRAK}

Penelitian ini bertujuan untuk menghasilkan produk minuman herbal yang diperkaya dari sari jahe dan temulawak. Selain itu juga bermanfaat sebagai acuan dalam pembuatan minuman herbal dari campuran jahe dan temulawak. Penelitian ini dilakukan di laboratorium Pengolahan dan Pengelolaan Hasil Pertanian Fakultas Pertanian Universitas Katolik Santo Thomas. Penelitian ini dilakukan dengan Rancangan Acak Lengkap (RAL) faktorial, yang terdiri dari dua faktor perlakuan. Faktor pertama konsentrasi tepung kedelai dengan sandi J, terdiri dari 4 taraf, yaitu: $\mathrm{J}_{0}=80: 20, \mathrm{~J}_{1}=70: 30, \mathrm{~J}_{2}=60: 40$, dan $\mathrm{J}_{3}=50: 50$. Faktor kedua lama pengeringan dengan sandi $\mathrm{L}$, terdiri dari 4 taraf, yaitu: $\mathrm{L}_{0}=0$ minggu, $\mathrm{L}_{1}=1$ minggu, $\mathrm{L}_{2}=2$ minggu; dan $\mathrm{L}_{3}=3$ minggu. Perlakuan perbandingan konsentrasi jahe dan temulawak berpengaruh sangat nyata terhadap keempat parameter ini yaitu total soluble solid (tss), $\mathrm{pH}$, nilai total asam, dan uji organoleptik. Perlakuan lama penyimpanan ( 0 minggu, 1 minggu, 2 minggu, dan 3 minggu) berpengaruh sangat nyata terhadap keempat parameter ini yaitu total soluble solid (tss), $\mathrm{pH}$, nilai total asam, dan uji organoleptik. Untuk total soluble solid (tss), dan nilai total asam mengalami peningkatan pada grafiknya, sedangkan $\mathrm{pH}$ dan uji organoleptik mengalami penurunan pada tiap minggunya. Dan untuk kombinasi perlakuan perbandingan konsentrasi jahe dan temulawak berpengaruh sangat nyata uji organoleptik, tetapi berpengaruh tidak nyata terhadap total soluble solid (tss), $\mathrm{pH}$ dan nilai total asam

Kata kunci : Minuman Herbal, Ekstrak Temulawak, Jahe, Lama Penyimpanan 


\section{PENDAHULUAN}

Minuman kesehatan sebagai salah satu produk yang sudah dikenal masyarakat, banyak dijumpai di pasaran dengan berbagai merek dan bentuk, seperti dalam bentuk cair, serbuk instan ataupun tablet. Kecenderungan masyarakat saat ini adalah lebih suka menggunakan produk dengan kemasan yang penyajiannya lebih praktis dan cepat, karena tidak perlu membutuhkan banyak waktu dalam mempersiapkannya.

Besarnya kandungan gizi dan komponen metabolit sekunder dalam jahe, menggugah peneliti untuk mencoba menuangkan ide dan inovasi menciptakan produk baru yaitu minuman kesehatan berbentuk serbuk/instan/herbal dengan memanfaatkan jahe. Ide pembuatan ini didasarkan pada sifat bahan yang memungkinkan untuk dapat dibuat minuman instan dengan mengacu pada proses pembuatan minuman instan atau minuman cair dalam kemasan botol secara umum.

Selain jahe, tumbuhan temulawak secara empirik juga banyak digunakan sebagai obat dalam bentuk tunggal maupun campuran untuk mengatasi gangguan saluran pencernaan, gangguan aliran getah empedu, sembelit, radang rahim, kencing nanah, kurang nafsu makan, obesitas, radang lambung, cacar air, ambeien, perut kembung, memulihkan kesehatan sehabis melahirkan (Afifah, 2015).

Temulawak sangat dianjurkan untuk dikonsumsi guna mencegah penyakit hati, termasuk hepatitis B yang menjadi salah satu faktor resiko timbulnya kanker hati. Semua khasiat tersebut diperoleh dari kandungan kurkumin, yaitu komponen metabolit yang berfungsi untuk menjaga dan menyehatkan hati/lever atau istilah medisnya hepatoprotektor.

Temulawak merupakan tanaman khas Indonesia yang memiliki potensi yang luar biasa untuk dikembangkan sebagai tanaman obat. Temulawak ini memiliki keunggulan setara dengan ginseng yang berasal dari Korea. Tidak heran, banyak orang menganggap, temulawak sebagai ginsengnya Indonesia. Daya tarik dari kedua komoditi ini penulis lakukan sebagai penelitian yang dilakukan untuk meningkatkan diversifikasi produk minuman herbal dari campuran jahe dengan temulawak.

\section{METODE PELAKSANAAN}

\section{Waktu dan tempat}

Penelitian dilakukan di

Laboratorium Pengolahan Pangan dan Pengolahan Hasil Pertanian, Program Studi Teknologi Hasil Pertanian, Fakultas Pertanian Universitas Katolik Santo Thomas Sumatera Utara, Medan. Pelaksanaan penelitian ini dilakukan pada bulan November 2020 hingga Februari 2021.

\section{Bahan}

Adapun bahan yang dipergunakan dalam penelitian ini adalah Jahe temulawak, gula aren, yang diperoleh dari pasar tradisional Melati, Medan.

\begin{abstract}
Alat
Alat-alat yang digunakan dalam penelitian ini adalah Erlenmeyer, gelas beaker, gelas ukur, blender, buret, batang pengaduk, kertas saring, oven, timbangan, kompor, labu ukur, loyang, pisau stainless steel, erlenmeyer, corong. Adapun reagensia yang digunakan adalah CMC (Carboxymethyl Cellulose), KI (Jenuh), $\mathrm{Na} 2 \mathrm{~S} 2 \mathrm{O} 3$, pati, $\mathrm{NaOH}$, pp $0,1 \%$.
\end{abstract}

\section{Rancangan Penelitian}

Penelitian ini dilakukan dengan metode Rancangan Acak Lengkap (RAL) Faktorial, dengan perlakuan sebagai berikut :

Faktor I : Konsentrasi Jahe (Zingiber officinale Rosc.) dan Temulawak (Curcuma xanthorrhiza Roxb.) dengan sandi (J) terdiri 
dari 4 taraf, yaitu:

$\mathrm{J} 0=$ Jahe $:$ Temulawak $=80 \%: 20 \%$

$\mathrm{J} 1=$ Jahe $:$ Temulawak $=70 \%: 30 \%$

$\mathrm{J} 2=$ Jahe $:$ Temulawak $=60 \%: 40 \%$

$\mathrm{J} 3=\mathrm{Jahe}:$ Temulawak $=50 \%: 50 \%$

Faktor II : Lama Penyimpanan dengan sandi

(L), terdiri dari 4 taraf yaitu :

L0 $=0$ Minggu

L1 $=1$ Minggu

L2 $=2$ Minggu

L3 $=3$ Minggu

\section{Pembuatan Sari Jahe}

Langkah-langkah yang dilakukan dalam pembuatan sari jahe yaitu: Jahe disortasi agar diperoleh bahan yang berkualitas, kemudian ditimbang sebanyak 1 $\mathrm{kg}$, dikupas dan dicuci bersih, lalu diiris dengan ukuran $2 \mathrm{~cm}$. Kemudian di campur dengan 5 liter air lalu diblender. Kemudian disaring untuk memisahkan sari dengan ampasnya, lalu sari jahe ditampung di dalam wadah gelas beaker.

\section{Pembuatan Sari Temulawak}

Temulawak disortasi agar diperoleh bahan yang berkualitas, kemudian ditimbang sebanyak $1 \mathrm{~kg}$, dikupas dan dicuci bersih, lalu diiris dengan ukuran 2 $\mathrm{cm}$. Kemudian di campur dengan 5 liter air lalu diblender. Kemudian disaring untuk memisahkan sari dengan ampasnya, lalu sari temulawak ditampung di dalam wadah beaker gelas.

\section{Pembuatan Minuman Herbal dari Campuran Sari Jahe dan Temulawak}

Sari jahe dan temulawak dicampur dengan perbandingan konsentrasi masing masing bahan yaitu, untuk konsentrasi pertama (J0) sebanyak $80 \mathrm{ml}$ sari jahe dengan penambahan temulawak sebanyak $20 \mathrm{ml}$. J1 sebanyak $70 \mathrm{ml}$ jahe dengan penambahan temulawak sebanyak $30 \mathrm{ml}$. J2 sebanyak $60 \mathrm{ml}$ jahe dengan penambahan temulawak sebanyak $40 \mathrm{ml}$. J3 sebanyak 50 $\mathrm{ml}$ jahe dengan penambahan temulawak sebanyak $50 \mathrm{ml}$. Setelah homogen ditambahkan bahan lainnya yaitu gula pasir sebanyak $4 \%$ gula aren $16 \%$, kayu manis $0,2 \%$, cengkeh $0.04 \%$, dan $\mathrm{CMC} 0,5 \%$ dari setiap jumlah perlakuan lalu dipanaskan sampai mendisih. Kemudian setelah minuman herbal tersebut mendidih, didinginkan dan dikemas ke dalam botol sebanyak $250 \mathrm{ml} /$ botol. Ditutup dengan menggunakan plastic wrap dan dilapisi aluminium foil, ditutup dan setelah itu dilakukan pasteurisasi selama 20 menit. Lalu kemasan dalam botol tersebut disimpan sesuai dengan variasi lama penyimpanan 0,1, 2 dan 3 minggu. Bahan disimpan dalam botol kemasan dalam keadaan steril. Selanjutnya dilakukan analisa sesuai parameter.

\section{Analisa Parameter dan Pengumpulan Data}

Untuk memperoleh data, dilakukan analisa terhadap sampel yang diperoleh. Parameter yang diamati adalah : Penentuan Total Soluble Solid (TSS), Uji Keasaman (pH), Nilai Total Asam dan Uji Organoleptik

\section{HASIL DAN PEMBAHASAN}

Berdasarkan hasil penelitian yang telah dilakukan menunjukkan bahwa perbandingan persentase antara konsentrasi sari jahe dan temulawak memberi pengaruh terhadap parameter minuman herbal yang diamati seperti yang disajikan pada Tabel 1 . berikut ini :

Tabel 1. Pengaruh Perbandingan Konsentrasi Jahe dan Temulawak Terhadap Parameter Minuman Herbal Yang Diamati

\begin{tabular}{ccccc}
\hline $\begin{array}{c}\text { Konsentrasi } \\
\text { Jahe dan }\end{array}$ & & Total & Total & Nilai \\
$\begin{array}{c}\text { Temulawak } \\
(\mathbf{J})\end{array}$ & $\mathrm{pH}$ & $\begin{array}{c}\text { Asam } \\
(\%)\end{array}$ & $\begin{array}{c}\text { Soluble } \\
\left({ }^{\circ} \text { Brix }\right)\end{array}$ & $\begin{array}{c}\text { Organoleptik } \\
\text { (Skor) }\end{array}$ \\
\hline
\end{tabular}


Volume 1 Nomor 2 April 2021

$\begin{array}{llllc}\mathrm{J}_{0} & 6.10 & 1.27 & 51.50 & 3.42 \\ \mathrm{~J}_{1} & 5.47 & 1.80 & 53.25 & 3.25 \\ \mathrm{~J}_{2} & 4.95 & 2.64 & 54.37 & 3.24 \\ \mathrm{~J}_{3} & 4.55 & 3.83 & 57.12 & 13.16\end{array}$

Pada Tabel 1. dapat dilihat bahwa nilai total asam, total soluble solid dan uji organoleptik tertinggi terdapat pada konsentrasi J3 (50\% Jahe : $50 \%$ Temulawak), sedangkan $\mathrm{pH}$ tertinggi diperoleh pada konsentrasi J0 (80\% Jahe : $20 \%$ Temulawak). Hal ini disebabkan oleh komponen gizi dan metabolit yang terkandung dalam jahe dan temulawak mempengaruhi zat gizi yang terdapat dalam produk akhir minuman herbal.

\section{Penentuan Total Soluble Solid (TSS)}

Total Soluble Solid (TSS) tertinggi terdapat pada perlakuan J3 sebesar 57.12 dan terendah pada perlakuan J0 yaitu sebesar 51.5. Hubungan antara konsentrasi jahe dan temulawak dengan TSS minuman herbal mengikuti persamaan regresi linier seperti yang disajikan pada gambar 1 . berikut ini :

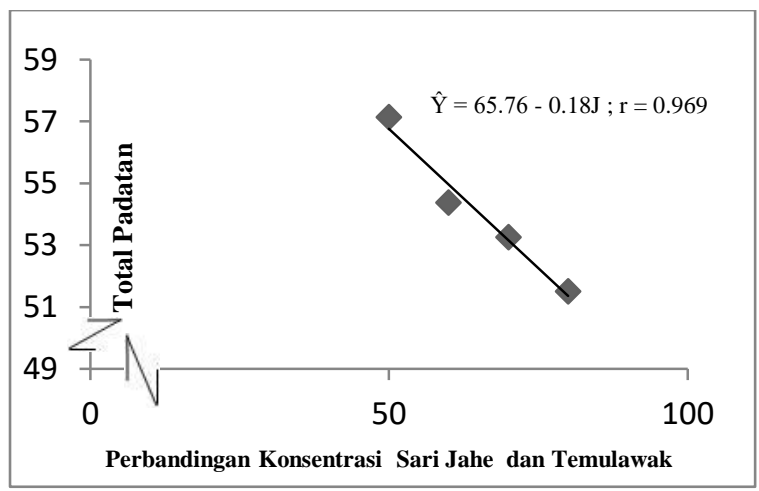

Gambar 1. Hubungan Antara Pengaruh Perbandingan Konsentrasi Sari Jahe dan Temulawak Terhadap Total Soluble Solid (TSS) Minuman Herbal

\section{Pengaruh Lama Penyimpanan Sari Jahe dan Temulawak Terhadap Nilai Total Soluble Solid Minuman Herbal}

Lama penyimpanan minuman herbal memberi pengaruh yang berbeda sangat nyata $(\mathrm{p}<0.01)$ terhadap TSS minuman herbal. Tingkat perbedaan $\mathrm{pH}$ akibat pengaruh konsentrasi jahe dan temulawak telah diuji dengan uji LSR (Least Significant Ranges). semakin lama penyimpanan minuman herbal maka TSS semakin meningkat. Total padatan terlarut tertinggi pada saat minggu ketiga yaitu sebanyak 55.750 Brix. Hubungan antara lama penyimpanan sari jahe dan temulawak dengan total soluble solid minuman herbal mengikuti persamaan regresi linier seperti yang disajikan pada gambar 2 . berikut ini :

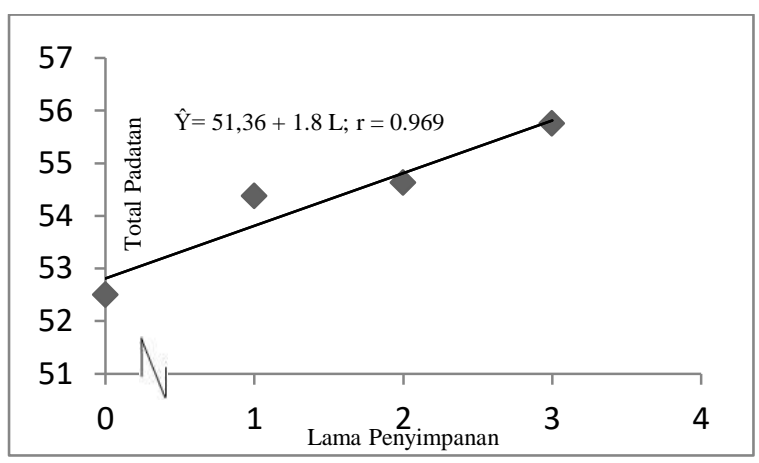

Gambar 2. Hubungan Lama Penyimpanan Terhadap Total Soluble Solid (TSS) Minuman Herbal.

Semakin lama penyimpanan, maka semakin banyak karbohidrat yang didegradasi karena kesempatan mikroba untuk mendegradasi karbohidrat menjadi senyawa organik semakin besar dan akhirnya mengakibatkan peningkatan total padatan terlarut. (Fardiaz, 1992). Lama penyimpanan pada produk minuman herbal ini, juga menyebabkan penurunan $\mathrm{pH}$. Asam yang terbentuk selama proses penyimpanan terjadi karena adanya aktivitas mikroba menyebabkan $\mathrm{pH}$ minuman herbal ini menurun. $\mathrm{pH}$ berhubungan erat dengan total asam, dimana kenaikan total asam menunjukkan penurunan $\mathrm{pH}$. 


\section{Pengaruh Perbandingan Konsentrasi Sari Jahe dan Temulawak Terhadap Uji Organoleptik Minuman Herbal}

Perbandingan konsentrasi sari jahe dan temulawak memberi pengaruh yang berbeda sangat nyata $(\mathrm{p}<0.01)$ terhadap uji organoleptik minuman herbal. Tingkat perbedaan uji organoleptik akibat pengaruh konsentrasi jahe dan temulawak telah diuji dengan uji LSR (Least Significant Ranges). Hubungan antara konsentrasi jahe dan temulawak dengan uji organoleptik minuman herbal mengikuti persamaan regresi linier seperti yang disajikan pada gambar 3 .

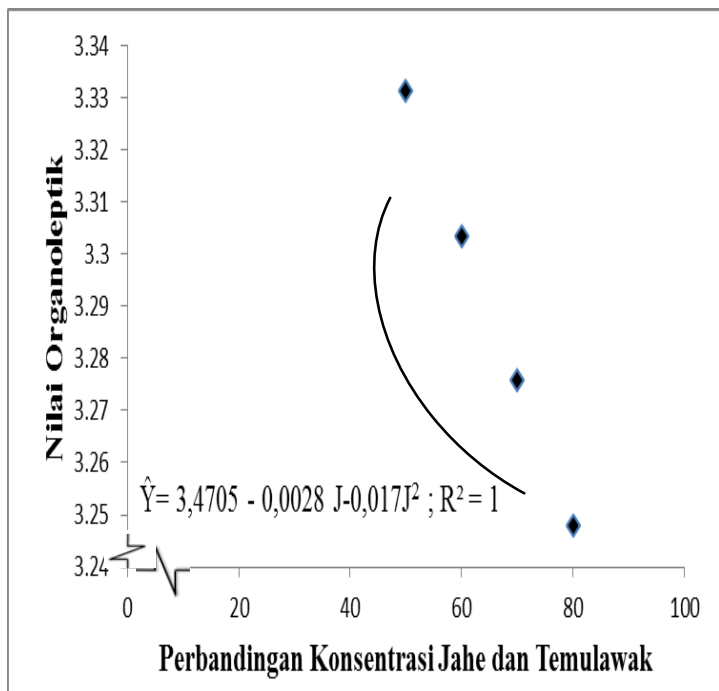

Gambar 3. Hubungan Konsentrası Jahe dan Temulawak dengan Nilai OrganoleptikTerhadap Minuman Herbal.

Pada gambar 3 menunjukkan bahwa semakin tinggi konsentrasi jahe dan temulawak maka uji organoleptik semakin menurun. Hal ini disebabkan karena temulawak pada minuman herbal ini memberikan warna dan bau yang kurang baik terhadap produk minuman herbal yang dihasilkan. Uji organoleptik tertinggi terdapat pada perlakuan $\mathrm{J}_{0}$ sebesar 3.42 dan terendah pada perlakuan $\mathrm{J}_{3}$ yaitu sebesar
3.24. Konsentrasi yang menunjukkan bahwa nilai organoleptik tertinggi adalah $\mathbf{J}_{0}$ (80\%:20\%).

\section{KESIMPULAN}

Berdasarkan hasil penelitian pembuatan minuman herbal dari campuran sari jahe dan temulawak dapat disimpulkan bahwa konsentrasi jahe dan temulawak member pengaruh beda sangat nyata $(\mathrm{p}<0.01)$ terhadap total soluble solid, $\mathrm{pH}$, nilai total asam, dan uji organoleptik. Pengaruh lama penyimpanan ( 0 minggu, 1 minggu, 2 minggu, dan 3 minggu) memberi pengaruh berbeda sangat nyata $(\mathrm{p}<0.01)$ terhadap total soluble solid, $\mathrm{pH}$, nilai total asam, dan nilai organoleptik. Untuk total soluble solid dan nilai total asam mengalami peningkatan, sedangkan $\mathrm{pH}$ dan nilai organoleptik mengalami penurunan.

Pengaruh interaksi perbandingan konsentrasi jahe dan temulawak dengan lama penyimpanan memberi pengaruh berbeda sangat nyata $(\mathrm{p}<0.01)$ terhadap nilai organoleptik, tetapi berpengaruh tidak nyata $(\mathrm{p}>0.05)$ terhadap total soluble solid, $\mathrm{pH}$ dan nilai total asam.

\section{UCAPAN TERIMA KASIH}

Penulis menyampaikan ucapan terimakasih kepada Rektor Universitas Katolik Santo Thomas, Dekan Fakultas Pertanian, Kaprodi Teknologi Hasil Pertanian, Kepala Laboratorium Teknologi Pengolahan Hasil Pertanian dan Laboratorium Mikrobiologi dan Bioproses Universitas Katolik Santo Thomas. 


\section{DAFTAR PUSTAKA}

Afifah, E. 2015. Khasiat dan Manfaat Temulawak: Rimpang Penyembuh Aneka Penyakit. Jakarta : Agro Media Pustaka.

Bahrun. 2011. Membuat Sari Pati Jahe. Jakarta: PT Balai pustaka.

Bangun, M. K. 1991. Rancangan Percobaan. Bagian Biometer Fakultas Pertanian USU-Press. Medan.

Buckle, K.A., Edwards, R. A., Fleet, G. H, and Wootton, M. 1987. Food Science dalam Ilmu Pangan. Penerjemah Hari Purnomo dan Adiono. Universitas Indonesia, Jakarta.

Cahyana, M., Ekaprasada, T., Herry, A. 2014. Isolasi Senyawa Antioksidan Kulit Batang Kayu Manis (Cinnamomum burmannii Nees exBlume), ISSN No. 0218-0781.

Departemen Kesehatan Republik Indonesia. 2010. Program Penanggulangan Anemia Gizi Pada Wanita Usia Subur (WUS). Depkes RI.

Fardiaz, S. 1992. Mikrobiologi Pangan I. Gramedia Pustaka Utama. Jakarta.

Hadi, S., 1985. Manfaat temu lawak ditinjau dari segi Kedokteran,Proceedings Simposium National Temulawak. UNPAD. Bandung.

Hasanah, M., Sukarman dan D. Rusmin. 2004. Teknologi Produksi Jahe. Buletin Penelitian Tanaman Rempah dan Obat. Litbang Pertanian.

Ketaren, S. 1986. Pengantar Teknologi: Minyak dan Lemak Pangan. Penerbit Universitas Indonesia. Jakarta.

Kusumah, R.A. 2007. Optimasi Kecukupan Panas Melalui Pengukuran Distribusi dan Penetrasi Panas Pada Formulasi Minuman Sari Buah Pala (Myristica fragrans HOUTT). Skripsi. Fateta. IPB. Bogor.
Matondang, L. 2005. Zinngiber officinale L. Pusat Penelitian dan Pengembagangan Obat Unas. Bandung.

Muchtadi, T. Dan Sugiono. 1993. Ilmu Pengetahuan Bahan Pangan. Pusat Antar Universitas Pangan dan Gizi, Institut Pertanian Bogor. Bogor.

Rahayu., 2001. Penuntun Praktikum Penilaian Organoleptik. Jurusan Teknologi Pangan dan Gizi. Fakultas Teknologi Pertanian. Bogor.

Sidik Moelyono, Muhtadi dan Rosa, 1999. Makalah Seminar: Temulawak (Curcuma xanthorrhiza Roxb) Botani, Etnobotani, Kimia, Farmakologi dan Pemanfaatannya dalam Kesehatan.

Sivakumar, D., Divine Njie, Hester Vermulen, Lise Korsten, Rosa Rolle. 2009. Horticultural Chain Management for Eastern and Southern Africa A Theoretical Manual. Food and Agriculture Organization of the United Nations and Commonwealth Secretariat, London.

Soebagio B, Soeryati S, Fauziah K. 2006. Pembuatan sediaan krim antiakne ekstrak rimpang temulawak (Curcuma Xanthorrhiza roxb). Farmasi FMIPA. UNPAD.

Sudarmadji, S., B. Haryono dan Suhardi, 1984. Prosedur Analisa untuk Bahan Makanan dan Pertanian. Liberty, Yogyakarta.

Sumiati. 1997. Minuman Berkhasiat dari Temulawak (Curcuma Xanthorriza Roxb.). Fakultas Teknologi Pertanian. IPB. Bogor.

Syarief, H. 1989. Percobaan-Percobaan Makanan. [Petunjuk Laboratorium]. Bogor: Pusat Antar Universitas Pangan dan Gizi, Institut Pertanian Bogor.

Tian and White, 1994. Antioxidant activity of Oat extracts in soybean and 
Volume 1 Nomor 2 April 2021

cottonseedoils. J. Am. Oil Chem.

Soc, 71 (1994), pp. 1079-1086 